\title{
Does organizational agility affect organizational learning capability? Evidence from commer- cial banking
}

\author{
Zaina Mustafa Mahmoud Hamad ${ }^{\mathrm{a} *}$ and Uğur Yozgat ${ }^{\mathrm{b}}$
}

${ }^{a} P h D$ in Business Administration, Gaziosmanpasa, Istanbul 34240, Turkey

${ }^{b}$ Professor, Department of Business Administration, Istanbul Kultur University, Istanbul 34191, Turkey

CH R O N I C L E

Article history:

Received: February 1, 2017

Received in revised format:

March 16, 2017

Accepted: May 17, 2017

Available online:

May 17, 2017

Keywords:

Organizational agility

Organizational learning capabil-

ity

Commercial banks

Organizational learning

Structural equation modeling

Jordan

\section{A B S T R A C T}

Both organizational agility and learning capability are prerequisites for organizational survival and success. This study explores the contribution of agility practices to organizational learning capabilities at the commercial banks in Jordan. To examine the proposed model, a sample of 158 employees within top and middle managements was used. Structural Equation Modeling was conducted for assessing validity and reliability of measurement instrument, evaluating model fit, and testing hypotheses. This study recognizes agility as a key element of learning facilitators. Findings affirm the strategic value of agility and conclude that administrators working within agile organizations would be able to acquire conditions that foster learning.

\section{Introduction}

Changes of business economy are occurring faster and more unexpectedly in recent years than ever (Sharifi \& Zhang, 1999). Wherefore, and early in the 1990s, agility emerged as the new solution (Alzoubi et al., 2011), as an essential capability (Goldman et al., 1995), and as a strategic weapon (Almahamid et al., 2010), for managing, operating and coping with this unpredicted turbulent environment. One company's effort to ensure agile capabilities is different from that of a similar competitor (Dove, 2001). Therefore, organizational agility (OA) should be built into the long range organizational planning (Ashrafi et al., 2006), and literature on and role of OA has begun to accumulate (Attafar et al., 2012). With this high competitive economy, the future would belong to those who have got a system of learning to serve the emerging market (Khan, 1999).

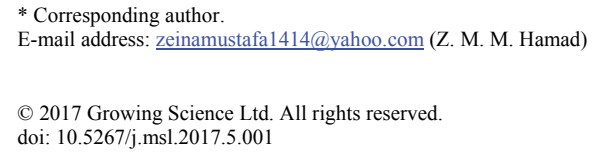


Organizational learning (OL) assumes a willingness to change (Sanaei \& Shahtalebi, 2014), and is deemed as crucial for organizations to grow and survive (Liao \& Wu, 2009). However, evidence of new skills and capabilities deepens our confidence that real learning is occurring (Senge et al., 1994). Accordingly, organizational learning capability (OLC), which is the organizational ability to practice the processes and activities that can manage learning effectively (Garvin, 1994), considered as an important way to assist the corporate drive to perform, grow and succeed (Hsu \& Fang, 2009) and as a strategic lever to gain competitive advantage (Goh, 2003). OLC is much talked about amongst academicians and managers (El Badawy et al., 2014) stressing its importance and what should managers take into account to develop it (Chiva \& Alegre, 2009). Proceeding from that there has been significantly growing interest in OA and OLC amongst both academic and practitioner communities, and drawing on previous literature such as Mavengere and Tikkamäki (2013) which affirms that OA promotes OL, and due to the dramatic growth and increase in Jordanian commercial banks and their importance in the national economic development (Zeitun \& Benjelloun, 2013); it has become necessary to investigate the potential relationships between OA and OLC. This paper presumes the existence of a relationship between OA and OLCs at the Jordanian commercial banks, examines the validity of the measurement scale, tests the proposed model, and extracts conclusions that could be useful for industry in general and for commercial banking in particular.

\section{Theoretical Background and Conceptual Model}

\subsection{Organizational Agility}

Turbulence in business environment has become the main cause of failure in the manufacturing industry (Lin et al., 2006). Surviving in this turbulence is possible if organizations are able to recognize their changing environments and respond properly to unexpected changes (Sharifi \& Zhang, 2001). Therefore, OA has emerged as a way for managing unforeseen organizational changes and managing risks (Khoramgah, 2012) and as a key competitive imperative (Tallon \& Pinsonneault, 2011) allowing organizations to survive in economic crises (Nijssen \& Paauwe, 2012). OA provides new measures for evaluating performance and new forms of commercial relationships (Zain et al., 2006). OA leads to better outcomes (Sambamurthy et al., 2007), creates competitive advantage (Brown \& Bessant, 2003), leads to cycle time reduction, mass customization, and virtual enterprise (Yu \& Heng, 2006), and decreases the disturbance caused by change transition (Dove, 1995). OA involves both the exploration and exploitation of opportunities for market balance (Sambamurthy et al., 2003). Exploitation is extension and refinement of existing competences, paradigms, and technologies, with positive, predictable, and proximate returns, while exploration is experimentation with new alternatives, with distant, negative, and uncertain returns, as implied by March (1991). Anyway, OA emerges from an exploration process more than from a prescriptive, mechanistic, and commoditized technique and technology (Galliers, 2007, p.11). There are different facets and varied views of agility in the literature (Yusuf et al., 1999), due to the multidimensionality and vagueness of this construct (Tsourveloudis \& Valavanis, 2002). Therefore, no commonly acceptable definition in academic communities exists ( $\mathrm{Su}, 2011)$. However, all agility definitions and its related concepts focus on organizational abilities to adapt its strategies, processes, and resources to respond to changes (Almahamid et al., 2010), and stress the ability to respond quickly to any unforeseen change (Zimmer et al., 2012). For example, agility is defined by Gunasekaran (1998) as "the capability to survive and prosper in a competitive environment of continuous and unpredictable change by reacting quickly and effectively to changing markets, driven by customer-designed products and services" (p.1223), and defined by Dove (2001) as "the ability to manage and apply knowledge effectively, so an organization has the potential to thrive in a continuously changing and unpredictable business environment" (p.9). Kassim and Zain (2004) define agility as "the ability of a firm to face and adapt proficiently in a continuously changing and unpredictable business environment" (p.174), while Overby et al. (2006) define it as "the ability of firms to sense environmental change and respond readily" (p.121). Similarly, Nafei (2016) asserts that it is "the organization's ability to achieve its objectives, through the development of its products increasing 
knowledge of its human resources, effecting the development of the organization and lightening its movement in a rapidly changing environment" (p.274). This paper expresses OA as; "The organizational ability to proactively detect and quickly and effectively respond to sudden and unpredictable changes within business environment". Agility practices are the methods or means used for obtaining agility capabilities (Sharifi \& Zhang, 2001). They affect the organizational ability to response quickly to changes (Yaghoubi \& Dahmardeh, 2010). Proceeding from that OA is a multidimensional construct that cannot be observed directly, and because it is necessary to use the agility practices - which considered by Charbonnier-Voirin (2011) as the most operational level of OA that contribute to its development and are applicable to all types of organizations; this paper adopts the dimensions of CharbonnierVoirin (2011) using the following agility practices.

2.1.1 Practices Directed Towards Mastering Change (PDTM): are practices for allowing the firm to thrive on change and uncertainty, providing it a flexible structure for a quick and proper utilization of resources (Goldman et al., 1995). Change is the most important factor of driving OA (Boudlaie et al., 2014). Mastering change is the organizational abilities to respond to changes and the actions undertaken for this purpose (Charbonnier-Voirin, 2011), and this is done by stimulating progress and being filled with technical, personal and organizational skills (Walick, 1997). Thus, these practices involve environmental scanning and sharing and learning insights which are supported by employee communication and training and development programs (Dyer \& Shafer, 1998). An agile organization grants personnel the ability of applying all essential resources for a profitable exploitation of opportunities, and creates motivated personnel for converting, routinely and rapidly, changes into new opportunities (Goldman et al., 1995).

2.1.2 Practices Valuing Human Resources (PVHR): these practices include empowering the work force, participating in making decisions, sharing knowledge, developing skills of collaborators, and enhancing creativity of employees (Charbonnier-Voirin, 2011). Agile manufacturing is supported by empowering people with skills and knowledge up (Ling, Tsuen, \& Hsu, 2008). Agile characteristics are key components of human resources strategy specially when searching for horizontal and vertical alignment (Dyer \& Shafer, 1998). Leveraging the impact of people and information, as explained by Goldman et al. (1995), means that management, in an agile firm, nourishes a firm culture that increases and powers the impact of people and information on operations, by providing the needed resources for personnel, distributing authority, and rewarding innovations.

2.1.3 Cooperative Practices (CP): are methods for encouraging internal cooperation and developing partnerships (Charbonnier-Voirin, 2011). These practices include enhancing internal and external cooperation such as establishing partnerships with suppliers, and considered the first choice of operational strategy for an agile firm (Goldman et al., 1995). Internal and external cooperation leads to synergy and plays an important role in developing OA (Sanchez \& Nagi, 2001). The agile firm should gain the strategy of opportunistic pool with other firms, even with competitors, in order to respond to market demands (Yaghoubi et al., 2011). Partnerships, cross-functional teams, empowerment, and business processes reengineering are all means for leveraging resources through cooperation (Goldman, et al., 1995).

2.1.4 Practices of Value Creation for Customers (PVCC): are practices for providing the company with knowledge about customer expectations and their development and for introducing innovative offerings (Charbonnier-Voirin, 2011). Value creation for customers or customer enrichment focuses on satisfying customers, by providing customers with solutions and ensuring the perception of customers of the value of these proposed solutions (Goldman, et al., 1995). Creating value for customers is to continuously provide different products and services for which the customer pays money (Yaghoubi et al., 2011).

\subsection{Organizational Learning Capability and Hypotheses Development}


There is an increasing need to know more about the most proper conditions for OL (Lähteenmäki et al., 2001). Achieving and enabling OL requires some managerial practices (Ulrich et al., 1993), and organizations should establish the internal conditions that foster OL (Goh, 2003). However, the learning facilitators and consequences of promoting learning are not the same for all organizations, as Tannenbaum (1997) expresses.

OLC is the managerial practices, or enablers and conditions that facilitate OL (Goh \& Richards, 1997) and enable an organization to learn (Popper \& Lipshitz, 1998). OLC is the ability that enables the process of OL by implementing factors that foster the OL process (Nwankpa \& Roumani, 2014). Similarly, OLC is the firm's activities for enhancing OL process (Tohidi et al., 2012). According to Hult and Ferrell (1997), OLCs are the factors that integrate the relationships and activities existing in the sub processes of OL at the cognitive levels of learning, while Jitnom and Ussahawanitchakit (2010) define OLC as the potential to explore and exploit knowledge through learning stream that creates likelihood the development, evolution and utilization of knowledge, while Alikhani and Fazlollahtabar (2014) consider OLC as a combination of the necessary tangible and intangible skills and resources for achieving competitive advantages. OLC is the capability of organizational members to learn (Hashim, 2013). Hsu and Fang (2009) identify OLC as the ability to acquire and convert a new knowledge and apply it to new product development with high production speed and competitive advantage. OLC is a source for organizational performance, according Prieto and Revilla (2006), Fernández-Mesa et al. (2012), and Akgün et al. (2014). OLC can enhance competitive advantage, as emphasized by Khan (1999) and Ho et al. (2013).

Embracing the competitive environment requires effective tools for success, such as OA and OL (Shahrabi, 2012), since the firm can detect opportunities through its capability to learn and gain knowledge (Teece, 2007). In other words, OL and OA play a key interrelated role in enhancing performance and organizations with both learning and agility capabilities can develop competitive advantage (Mavengere \& Tikkamäki, 2013). Agile leaders can learn actively and help others to learn (McKenzie \& Aitken, 2012); leadership agility achieves learning by supporting the knowledge management practices which address the collective learning achievement (McKenzie \& Aitken, 2012). Additionally, OA is required to develop and sustain OL competency (Dyer \& Shafer, 1998) because agile organizations are always prepared to learn (Shahrabi, 2012). OA promotes OL, in that as the organization senses and responds to the environmental pressures so it learns from the experience and thus develops OL (Mavengere \& Tikkamäki, 2013). Simultaneously, OLC is the processes and factors that facilitate or impede OL (DiBella et al., 1996). There is a lack and scarcity of previous related work addressing the linkage between OA and OLC. To fill this gap in the literature, this paper proposes that a relation may exist and hypothesizes that: H1. There is a significant and positive impact of OA (PDTM, PVHR, CP, and $P V C C$ ) on $O L C$.

OLC concept stresses the significance of the facilitating factors of OL (Chiva et al., 2006). ChivaGómez (2004) analyzes and proposes fifteen facilitating factors suggested by both the OL and the learning organization literatures, and claims that almost all of these factors determined by both literatures are universal; are perceived and applicable for all organizations and sectors. Chiva et al. (2007) group OL facilitating factors of Chiva-Gómez (2004), develop a new OLC measurement instrument with taking into account all the literatures involved in the facilitating factors, and identify the following five dimensions for OLC (facilitating factors of OL).

2.2.1 Experimentation (EX): is the level to which new suggestions and ideas are brought, presented, and dealt with sympathetically (Chiva et al., 2007). Experimentation is the most consistent managerial practice observed in learning organizations (Goh \& Richards, 1997). Experimentation is trying out new things, being curious about how things work, being able to play with things, and accepting failures (Nevis et al., 1995). Experimentation uses the scientific methods to systematically search for and test 
new knowledge (Garvin, 1994), and needs an organizational culture which increases the risk taking and supports the notion that one can learn from the experiments and mistakes of other ones (Slater \& Narver, 1995). Therefore, an organization is supposed to allow and encourage experimentation with new work methods (Senge, 1990), since learning barriers could be resulted from lack of experimentation (Schimmel \& Muntslag, 2009).

Making an agile workplace is required for experimentation, and an agile workplace is created by activities that achieve improvement through experimentation and learning (Joroff et al., 2003). OA can be designed into capability development through experimentation (Targeted News Service, 2016). Agile individuals experiment and implement new ideas on a continuous base (Dai, De Meuse, \& Tang, 2013). Accordingly, this paper hypothesizes that: H11. There is a significant impact of OA (PDTM, PVHR, $C P$, and PVCC) on Experimentation.

2.2.2 Risk Taking (RT): is defined by Wiklund and Shepherd (2003) as "committing resources to projects where the outcomes are unknown" (p.1309). Risk taking is the toleration and bearing of errors, uncertainties, failures, and ambiguity (Chiva et al., 2007), and organizations assuming risks and accepting mistakes could facilitate OL (Onağ et al., 2014). Risk taking causes learning from successes and mistakes which in turn leads to opening new and further opportunities (Vargas, 2013).Therefore, taking risks and exploring new novel product domains and markets promotes a learning culture (Anderson et al., 2009).

The risk-taking attitude of decision makers affects the overall level of OA (Mishra et al., 2014). Agile organizations look up to tolerate high risks; they must bear high risks in order to be agile (Lyytinen \& Rose, 2006). OA includes facing unpredictable changes. This may lead employees to collaborate for decreasing fears and obtaining openness which in turn would motivate taking new risks, according to Hurley and Hult (as cited in Mat \& Cherazak, 2011). Agile individuals readily take risks (Dai et al., 2013). Therefore, this research hypothesizes that: H12. There is a significant impact of OA (PDTM, PVHR, CP, and PVCC) on Risk taking.

2.2.3 Interaction with the External Environment (INTER): external environment is the factors that are not under the direct control of organizations (Chiva \& Algre, 2008). Interaction with external environment is the extent of relationships that organizations possess and adhere in their immediate environment (Alegre \& Chiva, 2008), and it includes achieving information about the organizational capacities and collecting and disseminating information (Abedi \& Eslami, 2014). Chiva and Alegre (2009) imply that learning occurs as a result of agents' connections and interactions. Alliances can boost and promote a unique learning atmosphere by bringing organizations together with unique capabilities and skills (Shukla, 2013). Therefore, organizations should deal with external shocks and set up relationships with external parties or agents (Vargas, 2013). Leaders can create OA by shared decision making and competitiveness, committing to communications and interactions, and bonding with the leading people (Ambrose, 2014). Enhancing partnerships within industry would produce distinguished teams who are leading in the agility areas (Targeted News Service, 2016). Agility includes sensing changes from both internal and external sources. This leads the entity to exhibit flexibility and apply previous experience and knowledge to learn from internal and external environment (Qumer \& Henderson-Sellers, 2006), and could in turn lead to alliances and bringing together the firms with unique skills and capabilities (Shukla, 2013). Therefore, this study hypothesizes that: H13. There is a significant impact of OA (PDTM, PVHR, CP, and PVCC) on interaction with the external environment.

2.2.4 Dialogue (DIA): is the uninterrupted collective inquiry, into the certainties, assumptions, and processes which form everyday experience, according to the definition of William Isaacs (as cited in Querubin, 2011). Dialogue is the interactions between internal actors (within the organizations) (Chiva \& Alegre, 2009). Dialogue is important for realizing learning (Gear et al., 2003), since dialogue creates 
collective perceptions and plural comprehensions (Oswick et al., 2000), promotes and encourages communication, leads to sharing the same conclusion between groups and teams (Mat \& Cherazak, 2011), and provides organizational members with opportunity to falsify premises and conclusions (Senge, 1990). Learning barriers could be due to absence of dialogue (Schimmel \& Muntslag, 2009). Therefore, organizational systems should promote teamwork and group problem-solving between employees and decrease the employees' dependence on the top managers (Goh \& Richards, 1997). Observing the interactions of business units can detect their ability to be agile (Ambrose, 2014). Dialogue builds a better industry team, which in turn, can achieve agility within capability development process (Targeted News Service, 2016). Communication and social interactions, such as facilitated debriefs, and individual and group conversations and dialogues, can achieve agility (Glymph, 2013). OA is communications-oriented (Qumer \& Henderson-Sellers, 2008). Agile organizations can affect OL through discussion, debate, idea exchange, and interaction between members (Worley, 2009). Agility facilitates group dialogue that encourages learning to daily practice (McKenzie \& Aitken, 2012). Hence, this study hypothesizes that: H14. There is a significant impact of OA (PDTM, PVHR, CP, and PVCC) on dialogue.

2.2.5 Participative Decision Making (PDM): is the amount of influence and power organizational members enjoying when making a particular decision (Cotton et al., 1988). It is the participation of the employees in establishing guidelines (Abedi \& Eslami, 2014). Workers should participate in decision making in order to achieve learning (Slater \& Narver, 1995). Participative decision making requires decreasing bureaucratic problem within organization (Mat \& Cherazak, 2011), and requires cohesiveness, trust and good relationship among members (Ho et al., 2013). Participative decision making is assessed in terms of its consequences, including employees' involvement in decisions, reduction of industrial conflict, and workforce democratization (Cotton et al., 1988). Participation of individuals with domain-specific experience in the process of decision making would enable managers to be strongly responsive to changes (Karuppan \& Kepes, 2006). Agile organizations share decision-making process and make it visible (Worley \& Lawler, 2010). Agile organizational culture is reflected in market focus with internal systems facilitating employee's empowerment and participation (Holbeche, 2011). Agility is characterized by an information infrastructure connecting the constituent parties and partners within a united network (Sanchez \& Nagi, 2001), and this connectivity might improve the coherence between members. Coherence, strong relations and trust between managers and employees are required for participative decision making (Ho et al., 2013). Thus, this study hypothesizes that: H15. There is a significant impact of OA (PDTM, PVHR, CP, and PVCC) on participative decision making.

\subsection{Proposed Structural Model}

According to the research hypothesis and its sub-hypotheses developed through literature review, this paper could come up with a conceptual model proposing OA to have an impact on OLC and its five dimensions. Fig. 1 shows the proposed model of this research.

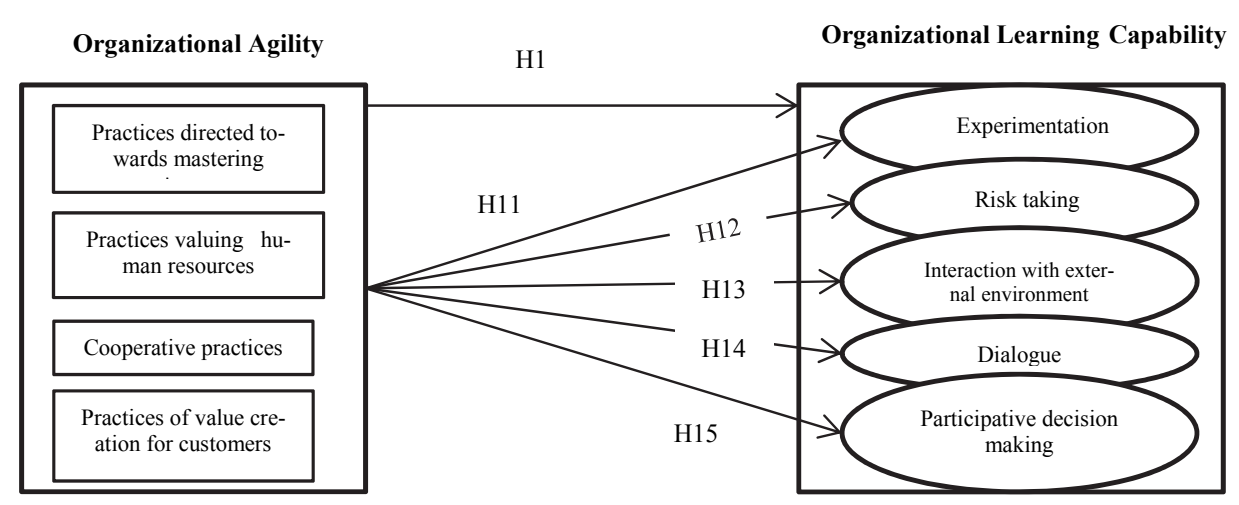

Fig. 1. Proposed Model of Research 


\section{Research Methodology}

Current research conducts quantitative approach. Descriptive method was used for the demographic variables analysis. SEM analysis was conducted for assessing the validity and reliability of the measurement instrument, for testing the relationships between latent variables and observed variables as well as for assessing the hypothesized relationships between latent variables within the proposed structural model.

\subsection{Data Collection}

Study population consists of the entire Jordanian banking sector while study sample is composed of all the commercial banks in Jordan. A questionnaire was used for collecting data from all employees of the top and middle level managements working within commercial banks in Jordan (13 commercial banks in total). After distributing (200) questionnaires, a total of (158) answered questionnaire were retrieved and valid for study. Five Likert Scale was used in the questionnaire, ranging from 1 (strongly disagree) to 5 (strongly agree). At the beginning, and as shown in table (1) below, demographic variables of the study sample are analysed.

\section{Table 1}

Descriptive analysis for the personal \& occupational characteristics of the study sample $(\mathrm{N}=158)$

\begin{tabular}{|c|c|c|c|}
\hline Variables & Categorization & Frequency & Percent \\
\hline \multirow{4}{*}{ Age } & 25 Years or less & 1 & 0.6 \\
\hline & 26 - less than 35 Years & 48 & 30.4 \\
\hline & 35 - less than 45 Years & 75 & 47.5 \\
\hline & 45 Years or more & 34 & 21.5 \\
\hline \multirow{2}{*}{ Gender } & Male & 90 & 57.0 \\
\hline & Female & 68 & 43.0 \\
\hline \multirow{5}{*}{ Qualification } & Diploma & 11 & 7.0 \\
\hline & Bachelor & 87 & 55.1 \\
\hline & High Diploma & 9 & 5.7 \\
\hline & Master & 47 & 29.7 \\
\hline & Doctorate & 4 & 2.5 \\
\hline \multirow{4}{*}{ Experience } & 5 Years or less & 8 & 5.1 \\
\hline & 6 - less than 15 Years & 90 & 57.0 \\
\hline & 15 - less than 25 Years & 44 & 27.8 \\
\hline & 25 Years or more & 16 & 10.1 \\
\hline \multirow{4}{*}{ Managerial level } & Manager & 43 & 27.2 \\
\hline & Assistant manager & 41 & 25.9 \\
\hline & Head of Division & 74 & 46.8 \\
\hline & Total & 158 & 100.0 \\
\hline
\end{tabular}

\subsection{Measures}

For measuring OA construct, this paper adopts the measurement scale of Charbonnier-Voirin (2011). A total of 16 items were employed to measure practices directed towards mastering change, such as the item "the firm builds possible development scenarios to prepare for change". For measuring practices valuing human resources, 12 items were selected such as the item "the firm rapidly transmits any new knowledge crucial for the firm to employees". However, 6 items were used for cooperative practices measurement, such as the item "the firm implements solutions to facilitate internal cooperation", while 12 items were chosen for measuring practices of value creation for customers, such as the item "the firm brings a customized response".

For measuring the construct of OLC, a total of 23 items were adopted from the literature. In particular, four items were used for measuring experimentation, such as the following item (Isaksen et al., 1999; Chiva et al., 2007): "the firm usually provides initiative a favorable response, so employees feel encouraged to generate new ideas". Three items were taken for risk taking measurement, such as the following item (Goh \& Richards, 1997; Onağ et al., 2014): “employees take risky decisions to perform better in their jobs". Three items were for assessing interaction with the external environment, such as 
the item (Pedler et al., 1997; Chiva et al., 2007): "the firm has systems and procedures for receiving, collating and sharing information from outside the firm". Seven items for dialogue were used, like the item (Hult \& Ferrell, 1997; Chiva et al., 2007): "the firm has cross-functional teamwork as a common practice", while six items were taken for measuring participative decision making, such as the item (Goh \& Richards, 1997; Onağ et al., 2014): "the firm's management often rewards innovative ideas that work".

Cronbach's alpha is used to determine the reliability and level of internal consistency among the elements comprising the nine constructs, as suggested by (Gregory, 2004). Reliability should be (0.60) or higher to indicate adequate convergence or internal consistency (Sekaran \& Bougie, 2010: 184). The results of scale reliability testing were at the acceptable levels as suggested by (Sekaran \& Bougie, 2010). The value of Cronbach's alpha for OA was 0.947 and for dimensions of OA were; $0.881,0.862$, 0.782 , and 0.888 respectively, while Cronbach's alpha value for OLC was 0.913 and for dimensions of OLC were; $0.838,0.724,0.794,0.813$, and 0.819 respectively.

\section{Data Analysis and Findings}

Using AMOS 20 software, confirmatory factor analysis (CFA) was conducted for testing the construct validity while path analysis was done for estimating the relationships between variables under study.

\subsection{CFA for Instrument Validation}

A scale of 69 items is developed from previous research and literature review, and a further attempt at refinement and validation of the factor structure was made using CFA for each construct (or factor). This provides a better understanding of what items truly measure the factors identified in the research model.

4.1.1 CFA and Measurement Model for OA: CFA was conducted for each dimension of OA. From each analysis, all item loadings were over 0.50 , with the exception of six items for practices directed towards mastering change, six items for practices valuing human resources, and three items for practices of value creation for customers which had factor loadings less than 0.50 . After running the second analysis, all the factor loadings were over 0.50 and all critical ratios were higher than 1.96. The model fit showed a good fit model. Table 2 represents the results of overall fit indices for each OA dimension.

After finishing the CFA for each individual variable for OA, the researchers estimated the CFA for the model as one unit, called the measurement model for OA. The measurement model was run with all the latent variables. All standardized regression weight values were ( $>0.5)$, and all critical ratios (C.R.) were (>1.96). Janssens et al. (2008) argue that the factor loading for each latent variable must be equal to or greater than $(0.50)$, and must also be significant $(C . R .=t$-value $>1.96)$. The measurement model with all constructs showed a good fit for all indices. See Table 2.

Table 2

Model fit estimates for OA

\begin{tabular}{ccccccc}
\hline VARIABLES & RMSEA & CMIN/DF & GFI & AGFI & CFI & NFI \\
\hline PDTM & 0.071 & 1.794 & 0.947 & 0.987 & 0.922 & 0.963 \\
PVHR & 0.055 & 1.481 & 0.985 & 0.937 & 0.993 & 0.981 \\
CP & 0.000 & 0.975 & 0.986 & 0.958 & 1.000 & 0.977 \\
PVCC & 0.079 & 2.056 & 0.934 & 0.865 & 0.962 & 0.929 \\
OA (All Constructs) & 0.078 & 2.548 & 0.988 & 0.940 & 0.911 & 0.905 \\
\hline
\end{tabular}

Convergent Validity and Composite Reliability were evaluated. The values of Average Variance Extracted (AVE) for constructs within the measurement model for OA dimensions are 0.69, 0.72, 0.57, and 0.77 respectively, as recommended by Malhotra \& Stanton (2004) who explained that AVE should be greater than $(0.50)$ to validate employing a construct. In addition, composite reliability (CR) indexes 
for constructs within the measurement model for OA dimensions are $0.85,0.84,0.78$, and 0.88 respectively, which are greater than (0.70) and thus indicate a satisfactory internal consistency, as recommended by Hair et al. (2010).

4.1.2 CFA and Measurement Model for OLC: CFA was conducted for each dimension of OLC. From each analysis, all item loadings were over 0.50 , with the exception of two items for dialogue and one item for participative decision making which had factor loadings less than 0.50. After running the second analysis, all the factor loadings were over 0.50 and all critical ratios were higher than 1.96. The model fit showed a good fit model. Table (3) shows the results of overall fit indices for each OLC dimension. After finishing the CFA for each individual variable for OLC, the researcher estimated the CFA for the model as one unit, called the measurement model for OLC. The measurement model was run with all the latent variables. All standardized regression weight values were $(>0.5)$, and all critical ratios (C.R.) were (>1.96). The measurement model with all constructs showed a good fit for all indices. See Table 3.

Table 3

Model fit estimates for OLC

\begin{tabular}{ccccccc}
\hline VARIABLES & RMSEA & CMIN/DF & GFI & AGFI & CFI & NFI \\
\hline EX & 0.073 & 4.810 & 0.989 & 0.947 & 0.990 & 0.978 \\
RT & 0.061 & 4.012 & 0.980 & 0.955 & 0.989 & 0.901 \\
INTER & 0.063 & 3.224 & 0.962 & 0.946 & 1.000 & 1.000 \\
DIA & 0.079 & 1.972 & 0.982 & 0.931 & 0.971 & 0.985 \\
PDM & 0.059 & 2.989 & 0.978 & 0.937 & 0.928 & 0.975 \\
OLC (All Constructs) & 0.042 & 1.282 & 0.909 & 0.905 & 0.976 & 0.901 \\
\hline
\end{tabular}

The values of AVE for constructs within the measurement model for OLC dimensions are $0.72,0.58$, $0.71,0.72$, and 0.67 respectively, and thus, are within acceptable limits that confirm the convergent validity. In addition, $\mathrm{CR}$ indexes for constructs within the measurement model for OLC dimensions are $0.82,0.73,0.80,0.83$, and 0.81 respectively, which indicate adequate construct reliability.

\subsection{Path Analysis for Testing Hypotheses}

The proposed structural model, presented previously in Fig. 1, shows a good fit for all indices. All values of overall fit indices were within acceptable limits. RMSEA $=0.075<0.08 ; \mathrm{CMIN} / \mathrm{DF}=1.876<$ 5.00; GFI, AGFI, CFI, NFI= 0.990, 0.989, 0.993, $0.980>0.90$ (Byrne, 2001; Hair et al., 2010). For testing hypotheses, significance of each path coefficient, estimate of standardized regression weight, standard error of regression weight, and critical ratio for regression weight were estimated. Table 4 presents the results of path analysis.

Table 4 shows that OA (PDTM, PVHR, CP, and PVCC) has a significant and positive impact on OLC at ( $p$ value $<0.05$ ) within commercial banks of Jordan; H1 is supported. Further, OA (PVHR, PVCC) has a significant and positive impact on experimentation at ( $p$ value $<0.05$ ); H11 is supported. OA (PDTM, PVHR, and CP) has a significant impact on risk taking at (p value $<0.05$ ); H12 is supported. Table 4 also shows that OA (PDTM and CP) has a significant and positive impact on Interaction with external environment at ( $\mathrm{p}$ value $<0.05$ ); H13 is supported. OA (CP, PVCC) has a significant and positive impact on dialogue at ( $\mathrm{p}$ value $<0.05$ ); H14 is supported, while OA (PVHR) has a significant and positive impact on participative decision making at ( $p$ value $<0.05$ ); H15 is supported. 
Table 4

Results of Hypotheses Testing

\begin{tabular}{|c|c|c|c|c|c|c|}
\hline \multirow{2}{*}{ Hypothesis } & \multicolumn{2}{|c|}{ Regression Weights } & \multirow{2}{*}{ Estimate } & \multirow{2}{*}{ SE } & \multirow{2}{*}{ C.R. } & \multirow{2}{*}{$P$ value } \\
\hline & From & To & & & & \\
\hline \multirow[t]{5}{*}{ H1 } & $\mathbf{O A}$ & OLC & 0.925 & 0.130 & 7.325 & $* * *$ \\
\hline & PDTM & OLC & 0.246 & 0.063 & 3.011 & 0.003 \\
\hline & PVHR & OLC & 0.321 & 0.050 & 4.067 & $* * *$ \\
\hline & $\mathrm{CP}$ & OLC & 0.294 & 0.049 & 3.773 & $* * *$ \\
\hline & PVCC & OLC & 0.180 & 0.048 & 2.234 & 0.025 \\
\hline \multirow[t]{5}{*}{ H11 } & $\mathbf{O A}$ & EX & 0.628 & 0.132 & 7.513 & $* * *$ \\
\hline & PDTM & EX & 0.094 & 0.103 & 1.069 & 0.285 \\
\hline & PVHR & EX & 0.329 & 0.078 & 4.009 & $* * *$ \\
\hline & $\mathrm{CP}$ & $\mathrm{EX}$ & 0.021 & 0.079 & 0.253 & 0.800 \\
\hline & PVCC & EX & 0.247 & 0.080 & 2.784 & 0.005 \\
\hline \multirow[t]{5}{*}{ H12 } & $\mathbf{O A}$ & RT & 0.576 & 0.182 & 6.755 & $* * *$ \\
\hline & PDTM & RT & 0.186 & 0.146 & 2.000 & 0.046 \\
\hline & PVHR & RT & 0.297 & 0.111 & 3.435 & $* * *$ \\
\hline & $\mathrm{CP}$ & RT & 0.207 & 0.112 & 2.394 & 0.017 \\
\hline & PVCC & RT & -0.091 & 0.114 & -0.976 & 0.329 \\
\hline \multirow[t]{5}{*}{ H13 } & OA & INTER & 0.584 & 0.157 & 6.973 & $* * *$ \\
\hline & PDTM & INTER & 0.275 & 0.125 & 3.053 & 0.002 \\
\hline & PVHR & INTER & 0.117 & 0.094 & 1.400 & 0.162 \\
\hline & CP & INTER & 0.337 & 0.095 & 4.034 & $* * *$ \\
\hline & PVCC & INTER & -0.077 & 0.097 & -0.848 & 0.397 \\
\hline \multirow[t]{5}{*}{ H14 } & $\mathbf{O A}$ & DIA & 0.658 & 0.134 & 7.833 & $* * *$ \\
\hline & PDTM & DIA & 0.125 & 0.104 & 1.416 & 0.157 \\
\hline & PVHR & DIA & 0.160 & 0.079 & 1.949 & 0.051 \\
\hline & $\mathrm{CP}$ & DIA & 0.252 & 0.080 & 3.078 & 0.002 \\
\hline & PVCC & DIA & 0.185 & 0.081 & 2.088 & 0.037 \\
\hline \multirow[t]{5}{*}{ H15 } & $\mathbf{O A}$ & PDM & 0.592 & 0.143 & 7.017 & $* * *$ \\
\hline & PDTM & PDM & 0.137 & 0.117 & 1.472 & 0.141 \\
\hline & PVHR & PDM & 0.203 & 0.089 & 2.350 & 0.019 \\
\hline & $\mathrm{CP}$ & PDM & 0.118 & 0.089 & 1.371 & 0.171 \\
\hline & PVCC & PDM & 0.178 & 0.091 & 1.909 & 0.056 \\
\hline
\end{tabular}

\section{Conclusions, Implications, and Future Research}

Few researches pay attention to organization spiritual assets (Bahrami et al., 2016) such as OA and OLC, and related research at the Middle East area, especially in the banking sector of Arab countries, is limited. Commercial banking in developing countries, such as Jordan, is considered by Somashekar (2009) as the backbone of the economy. This study highlights the relation between OA and facilitating factors of OL at Jordanian commercial banks, in order to realize better competitive advantage, higher profitability, and increased probability of organizational survival. Findings affirm the strategic value of OA and its importance in the development of strategic capabilities, such as OLC which is considered by Jerez-Gómez et al. (2005) as a strategic capability. Findings provide a substantial contribution to knowledge in fields of both agility and OL. Findings, through a quantitative approach, provide an empirical justification for a structural model that identifies the enhancing impact of OA on OLC, and investigate the role OA with its dimensions play in strengthening each of the five learning facilitators. This research, through CFA, validates the scales used for measuring variables under study within Jordanian commercial banking sector. Findings provide an empirical support for the four practices of OA operationalized in Charbonnier-Voirin (2011), and empirical bolster for the five facilitators of OL operationalized in Chiva et al. (2007). This paper proposes practical implications that assist managers and practitioners within commercial banking, particularly the Jordanian one, in acquiring a more scientific understanding of importance of OA activities, and provide them with directives regarding the opportunities of enhanced learning facilitators that OA practices can offer in the Jordanian turbulence economic environment. Findings call for the need to establish an agile organization with taking into consideration the practices of mastering change, valuing HR, cooperation, and customer satisfaction, which in turn, can support the processes of experimentation and openness, taking and accepting risks, interacting with external through partnerships, conversations and internal communications, and employee empowerment. Agility doesn't just happen; it has to be deliberately pursued (Shafer et al., 2000). Decision makers are recommended to facilitate the organizational transformation with OA through: (1) improving the ability of the firm to solve problems and make better decisions by facilitating the inclusion of knowledge sharing systems and consolidating IT systems and practices; (2) taking advantage of their 
limited resources for satisfying customer needs and exercising processes and procedures that push them to perform continually. This could be established by reducing unnecessary expenses and non-essential activities; and (3) achieving collaboration internally and externally and applying better performance measures, which in turn would decrease the conflict of interests and goals within the organization, and thus break the change restrictions and barriers. Further, professionals should recognize how the five facilitators of learning, being enhanced by OA, may lead organizations to; find ways for promoting work processes (Goh \& Richards, 1997), beat and get rid of the strict bureaucratic system being practiced in the organization (Farsani et al., 2012), protect competitive advantages (Pucik, 1988), and increase innovation (Vargas, 2013), and business performance (Som et al., 2010).

Only commercial banks were included in the survey, excluding the banks falling in the other classifications stated by the Central Bank of Jordan, and this may limit external validity. Findings may be subjected to certain characteristics of this specific economy- Jordanian economy- which is a relatively small economy in a developing country. The explored relationships between variables in question were only among the commercial banking sector which may also limit external validity. Hypotheses were tested among the top and middle management levels and this may constitute methodological limitation as the other stakeholders are not taken into account. Caution should be taken when conclusions are to be generalized to other types of Jordanian banks or to the banking sector as a whole, or when to be generalized to banks in wider or different regional and cultural boundaries, or even to other industries or sectors. Therefore, this research recommends for further research surveying the Jordanian Islamic banks and foreign banks. Cross-national studies may be conducted to compare the study results (Onağ et al., 2014). Future research is recommended at commercial banks of other cultures or other countries of origin which might produce results differently from current findings. Further research may survey other industrial fields, such as mobile telecommunications sector, IT sector, universities and education establishments, or ministries and governmental institutions, to verify the model applicability for other business contexts. Structural model may be tested at a more collective level, by including the lowerlevel management, such as supervisors, controllers, and treasurers. A small component of a cause and effect quantitative study can be qualitatively studied to result in a better understanding of the cause and effect results of a quantitative study (Castellan, 2010). Future research might conduct a quantitative approach along with qualitative research, such as making observations and conducting interviews. Future research might resort to different measures and scales validated by previous studies in order to evaluate constructs under study. Individual agility is the perceived improvement in personal agility (Chung et al., 2014). Future research has the chance to look into the impact of individual agility on OLC, and may also explore the relation of business unit agility with other organizational capabilities for enhancing OLC. OL orientation or OL intensity, which could be affected by OA, may also be taken into consideration.

\section{Acknowledgement}

No funding sources had involved in conducting this research.

\section{References}

Abedi, S. H., \& Eslami, H. (2014). The relationship between organizational virtuousness and social capital: the mediator role of organizational learning (case study: ministry of economic affairs and finance of Yazd). Interdisciplinary Journal of Contemporary Research in Business, 5(9), 524-533.

Akgün, A. E., İmamoğlu, S. Z., Koçoğlu, I., İnce, H., \& Keskin, H. (2014). Bridging Organizational Learning Capability and Firm Performance through Customer Relationship Management. Procedia - Social and Behavioral Sciences, 10th International Strategic Management Conference, 150, 531-540.

Alegre, J., \& Chiva, R. (2008). Assessing the impact of organizational learning capability on product innovation performance: An empirical test. Technovation, 28(6), 315-326.

Alikhani, M., \& Fazlollahtabar, H. (2014). A Mathematical Model for Optimizing Organizational Learning Capability. Advances in Operations Research, 2014, 1-12. 
Almahamid, S., Awwad, A., \& McAdams, A. C. (2010). Effects of organizational agility and knowledge sharing on competitive advantage: an empirical study in Jordan. International Journal of Management, 27(3), 387-404.

Alzoubi, A. H., Al-otoum, F. J., \& Albatainh, A. F. (2011). Factors Associated Affecting Organization Agility on Product Development. International Journal of Research and Reviews in Applied Sciences (IJRRAS), 9(3), 503-516.

Ambrose, J. (2014). The relationship between learning, workforce agility, and business performance (White Paper). Irealand: Skillsoft.

Anderson, B. S., Covin, J. G., \& Slevin, D. P. (2009). Understanding the relationship between entrepreneurial orientation and strategic learning capability: an empirical investigation. Strategic Entrepreneurship Journal, 3(3), 218-240.

Ashrafi, N., Xu, P., Kuilboer, J., \& Koehler, W. (2006, January). Boosting enterprise agility via IT knowledge management capabilities. In Proceedings of the 39th Annual Hawaii International Conference on System Sciences (HICSS'06) (Vol. 2, pp. 46a-46a). IEEE.

Attafar, A., Ghandehari, M., \& Momeni, G. (2012). Study of Required Organizational Base for Implementation of Agility Strategy in Organizations (Case Study: Industrial Entekhab Group). Interdisciplinary Journal of Contemporary Research in Business, 3(11), 141-150.

Bahrami, M. A., Kiani, M. M., Montazeralfaraj, R., Zadeh, H. F., \& Zadeh, M. M. (2016). The Mediating Role of Organizational Learning in the Relationship of Organizational Intelligence and Organizational Agility. Osong Public Health and Research Perspectives, 1-7.

Boudlaie, H., Golabdoust, A., \& Golabdoust, T. (2014). An Analysis of Organizational Intelligence and Organization Agility Status in Tehran University of Medical Sciences. International Business and Management, 9(2), 100-109.

Brown, S., \& Bessant, J. (2003). The manufacturing strategy-capabilities links in mass customisation and agile manufacturing-an exploratory study. International Journal of Operations \& Production Management, 23(7), 707-730.

Byrne, B. M. (2001). Structural equation modeling with AMOS. New Jersey, US: Lawrence Erlbaum Associates.

Castellan, C. M. (2010). Quantitative and qualitative research: A view for clarity. International Journal of Education, 2(2), 1-14.

Charbonnier-Voirin, A. (2011). The development and partial testing of the psychometric properties of a measurement scale of organizational agility.M@n@gement,14(2),119-156.

Chiva, R., \& Alegre, J. (2008). Emotional intelligence and job satisfaction: the role of organizational learning capability. Personnel Review, 37(6), 680-701.

Chiva, R., \& Alegre, J. (2009). Organizational learning capability and job satisfaction: An empirical assessment in the ceramic tile industry. British Journal of Management, 20(3), 323-340.

Chiva, R., Alegre, J., \& Lapiedra, R. (2006, March). Development and validation of an instrument to measure organizational learning capability. In International Conference on Organizational Learning, Knowledge, and Capabilities (OLKC).University of Warwick.

Chiva, R., Alegre, J., \& Lapiedra, R. (2007). Measuring organizational learning capability among the workforce. International Journal of Manpower, 28(3/4), 224-242.

Chiva-Gómez, R. (2004). The facilitating factors for organizational learning in the ceramic sector. Human Resource Development International, 7(2), 233-249.

Chung, S., Lee, K. Y., \& Kim, K. (2014). Job performance through mobile enterprise systems: The role of organizational agility, location independence, and task characteristics. Information \& Management, 51(6), 605-617.

Cotton, J. L., Vollrath, D. A., Foggat, K. L., Lengnick-Hall, M. L., \& Jennings, K. R. (1988). Employee participation: diverse forms and different outcomes. Academy of Management Review, 13(1), 8-22.

Dai, G., De Meuse, K. P., \& Tang, K. Y. (2013). The role of learning agility in executive career success: The results of two field studies. Journal of Managerial Issues, 25(2), 108-131.

Dibella, A. J., Nevis, E. C., \& Gould, J. M. (1996). Understanding organizational learning capability. Journal of Management Studies, 33(3), 361-379.

Dove, R. (1995). Measuring agility: The toll of turmoil. Production, 107(1), 12-14. 
Dove, R. (2001). Response ability: the language, structure, and culture of the agile enterprise. New York: John Wiley \& Sons, Inc.

Dyer, L., \& Shafer, R. A. (1998). From Human Resource Strategy to Organizational Effectiveness: Lessons from Research on Organizational Agility (CAHRS Working Paper No: 98-12). Ithaca, NY: Cornell University, ILR School, Center for Advanced Human Resource Studies (CAHRS).

El Badawy, T. A., Srivastava, S., \& Sadek, M. B. (2014). Assessing the relationship between emotional intelligence, job satisfaction and organizational learning capability in private higher educational institutions in Egypt and India: A comparative study. International Journal of Business Administration, 5(6), $38-47$.

Farsani, J. J., Bidmeshgipour, M., Habibi, M., \& Rashidi, M. M. (2012). Intellectual capital and organizational learning capability in Iranian active companies of petrochemical industry. Procedia-Social and Behavioral Sciences, 62, 1297-1302.

Fernández-Mesa, A., Alegre-Vidal, J., Chiva-Gómez, R., \& Gutiérrez-Gracia, A. (2012). Design Management Capability: Its mediating Role between OLC and Innovation Performance in SMEs. Management, 25(473), 490.

Galliers, R. D. (2007). Strategizing for agility: Confronting information systems inflexibility in dynamic environments. In Desouza K. C. (Eds.), Agile Information systems: conceptualization, construction, and management (pp. 1-15). UK: Routledge.

Garvin, D. A. (1994). Building a learning organization. Business Credit, 96(1), 19-28.

Gear, T., Vince, R., Read, M., \& Leonard Minkes, A. (2003). Group enquiry for collective learning in organizations. Journal of Management Development, 22(2), 88-102.

Glymph, M. (2013). Exploring How Communication Shapes Organizing And Agility: A Business Simulation (Master thesis). Available from ProQuest Information and Learning Company, UMI Dissertations Publishing, 2013. (UMI No. 1543406)

Goh, S. C. (2003). Improving organizational learning capability: lessons from two case studies. The Learning Organization, 10(4), 216-227.

Goh, S., \& Richards, G. (1997). Benchmarking the learning capability of organizations. European Management Journal, 15(5), 575-583.

Goldman, S., Nageel, R., \& Preiss, K. (1995). Agile Competitors and Virtual Organizations: Strategies for Enriching the Customer. New York: Van Nostrand Reinhold.

Gregory, R. J. (2004). Psychological testing: History, principles, and applications. Allyn \& Bacon.

Gunasekaran, A. (1998). Agile manufacturing: enablers and an implementation framework. International Journal of Production Research, 36(5), 1223-1247.

Hair, J. F., Black, W. C., Babin, B. J., \& Anderson, R. E. (2010). Multivariate Data Analysis (7th ed.). Upper Saddle River, NJ: Pearson Prentice Hall.

Hashim, A. (2013). A Conceptual Framework for Antecedents and Consequence of Organizational Learning Capability. Information Management and Business Review, 5(12), 577-583.

Ho, T. H. F., Ahmad, N. H., \& Thurasamy, R. (2013). Learn and thou shall thrive: advancing a model of workplace familism and organizational learning capability in small and medium enterprise (SMEs) manufacturers in Malaysia. Business Strategy Series, 14(5/6), 151-159.

Holbeche, L. S. (2011). Organizational Agility. Retrieved from www.uhr.ac.uk/uploadedfiles/Documents/UHR_PDF\%20OA.pdf

Hsu, Y. H., \& Fang, W. (2009). Intellectual capital and new product development performance: The mediating role of organizational learning capability. Technological Forecasting and Social Change, 76(5), 664-677.

Hult, G. T. M., \& Ferrell, O. C. (1997). Global organizational learning capacity in purchasing: Construct and measurement. Journal of Business Research, 40(2), 97-111.

Isaksen, S. G., Lauer, K. J., \& Ekvall, G. (1999). Situational outlook questionnaire: a measure of the climate for creativity and change. Psychological Reports, 85, 665-674.

Janssens, W., Wijnen, K., Pelsmacker, P., \& Kenhove, P. (2008). Marketing Research with SPSS. Harlow: Prentice-Hall.

Jerez-Gómez, P., Céspedes-Lorente, J., \& Valle-Cabrera, R. (2005). Organizational learning and compensation strategies: Evidence from the Spanish chemical industry. Human Resource Management, 44(3), 279-299. 
Jitnom, S., \& Ussahawanitchakit, P. (2010). Strategic learning capability, firm performance and sustainable growth: an empirical study of auto spare part manufacturing businesses in Thailand. International Journal of Business Strategy, 10(4), 107-131.

Joroff, M. L., Porter, W. L., Feinberg, B., \& Kukla, C. (2003). The agile workplace. Journal of Corporate Real Estate, 5(4), 293-311.

Karuppan, C. M., \& Kepes, S. (2006). The strategic pursuit of mix flexibility through operators' involvement in decision making. International Journal of Operations \& Production Management, 26(9), 10391064.

Kassim, N. M., \& Zain, M. (2004). Assessing the measurement of organizational agility. Journal of American Academy of Business, Cambridge, 4(1/2), 174-177.

Khan, S. A. (1999). Building organizational learning capability. Indian Journal of Industrial relations, 35(1), 74-84.

Khoramgah, S. S. (2012). Analysis Relationship between Entrepreneurship \& Organizational Agility (Case study: Tehran Selected Entrepreneurs). Interdisciplinary Journal of Contemporary Research in Business, 3(11), 860-868.

Lähteenmäki, S., Toivonen, J. \& Mattila, M. (2001). Critical Aspects of Organizational Learning Research and Proposals for Its Measurement. British Journal of Management, 12, 113-129.

Liao, S. H., \& Wu, C. C. (2009). The relationship among knowledge management, organizational learning, and organizational performance. International Journal of Business and Management, 4(4), 64-76.

Lin, C. T., Chiu, H., \& Tseng, Y. H. (2006). Agility evaluation using fuzzy logic. International Journal of Production Economics, 101, 353-368.

Ling, Z., Tsuen, L. \& Hsu, H. (2008). The qualitative and quantitative models for performance measurement systems: The agile service development. Journal of Quality \& Quantity, 8, 445-479.

Lyytinen, K., \& Rose, G. M. (2006). Information system development agility as organizational learning. European Journal of Information Systems, 15(2), 183-199.

Malhotra, N. K., \& Stanton, S. C. (2004, August). Validating Inter-Object Interaction in Object Oriented Designs. In: 4th IASTED International Conference on Modelling, Simulation and Optimization (pp. 241 246). Kauai, Hawaii, USA.

March, J. G. (1991). Exploration and exploitation in organizational learning. Organization Science, 2(1), 71-87.

Mat, A., \& Cherazak, R. C. (2011). The influence of organizational learning capability on success of technological innovation (product) implementation with moderating effect of knowledge complexity. International Journal of Business and Social Science, 2(17), 217-225.

Mavengere, N. B., \& Tikkamäki, K. (2013, July). Organizational Learning, Agility and Social Technologies for Enhanced Organizational Performance. In: X World Conference on Computers in Education (pp. 173-181). Toruń, Poland.

McKenzie, J., \& Aitken, P. (2012). Learning to lead the knowledgeable organization: Developing leadership agility. Strategic HR Review, 11(6), 329-334.

Mishra, S., Sankar Mahapatra, S., \& Datta, S. (2014). Agility evaluation in fuzzy context: influence of decision-makers' risk bearing attitude. Benchmarking: An International Journal, 21(6), 1084-1119.

Nafei, W. A. (2016). The Effect of Organizational Agility on Quality of Work Life: A Study on Commercial Banks in Egypt. International Journal of Business and Management, 11(6), 271-285.

Nevis, E., Dibella, A. J., \& Gould, J. M. (1995). Understanding organizations as learning systems. Sloan Management Review, 36(2), 73-85.

Nijssen, M., \& Paauwe, J. (2012). HRM in turbulent times: how to achieve organizational agility?. The International Journal of Human Resource Management, 23(16), 3315-3335.

Nwankpa, J., \& Roumani, Y. (2014). Understanding the link between organizational learning capability and ERP system usage: An empirical examination. Computers in Human Behavior, 33, 224-234.

Onağ, A. O., Tepeci, M., \& Başalp, A. A. (2014). Organizational Learning Capability and its Impact on Firm Innovativeness. Procedia-Social and Behavioral Sciences, 150, 708-717.

Oswick, C., Anthony, P., Keenoy, T., Mangham, I. L., \& Grant, D. (2000). A dialogic analysis of organizational learning. Journal of Management Studies,37(6), 887-902.

Overby, E., Bharadwaj, A., \& Sambamurthy, V. (2006). Enterprise agility and the enabling role of information technology. European Journal of Information Systems, 15(2), 120-131. 
Pedler, M., Burgoyne, J., \& Boydell, T. (1997). The Learning Company: A Strategy for Sustainable Development. London: McGraw-Hill.

Popper, M., \& Lipshitz, R. (1998). Organizational learning mechanisms a structural and cultural approach to organizational learning. The Journal of Applied Behavioral Science, 34(2), 161-179.

Prieto, I. M., \& Revilla, E. (2006). Learning capability and business performance: a non-financial and financial assessment. The Learning Organization, 13(2), 166-185.

Pucik, V. (1988). Strategic alliances, organizational learning, and competitive advantage: The HRM agenda. Human Resource Management, 27(1), 77-93.

Querubin, C. (2011, September). Dialogue: Creating shared meaning and other benefits for business. In Proceedings of the 55th Annual Meeting of the ISSS-2011(Vol. 55, No. 1), UK: Hull.

Qumer, A., \& Henderson-Sellers, B. (2006, February). Measuring agility and adoptability of agile methods: a 4-dimensional analytical tool. In Proceedings of the IADIS International Conference Applied Computing (pp. 503-507). IADIS.

Qumer, A., \& Henderson-Sellers, B. (2008). An evaluation of the degree of agility in six agile methods and its applicability for method engineering. Information and Software Technology, 50(4), 280-295.

Sambamurthy, V., Bharadwaj, A., \& Grover, V. (2003). Shaping agility through digital options: Reconceptualizing the role of information technology in contemporary firms. MIS Quarterly, 27(2), 237-263.

Sambamurthy, V., Wei, K. K., Lim, K., \& Lee, D. (2007). IT-enabled organizational agility and firms' sustainable competitive advantage. $28^{\text {th }}$ International Conference on Information Systems (ICIS), ICIS 2007 Proceedings (pp. 91).

Sanchez, L. M., \& Nagi, R. (2001). A review of agile manufacturing systems. International Journal of Production Research, 39(16), 3561-3600.

Sanaei, S., \& Shahtalebi, B. (2014). The Relationship Between Organizational Learning And Readiness For Change (Willingness To Change) Among High School Teachers. Kuwait Chapter of the Arabian Journal of Business and Management Review, 3(12), 226-231.

Schimmel, R., \& Muntslag, D. R. (2009). Learning barriers: a framework for the examination of structural impediments to organizational change. Human Resource Management, 48(3), 399-416.

Sekaran, U., \& Bougie, R. (2010). Research methods for business: A skill building approach (5th ed.). West Sussex, UK: John Wiley \& Sons Ltd.

Senge, P. M. (1990). The Fifth Discipline: The Art and Practice of the Learning Organization. New York: Doubleday Currency.

Senge, P. M., Kleiner, A., Roberts, C., Ross, R. B., \& Smith, B. J. (1994). The fifth discipline field book: Strategies and tools for building a learning organization. UK: Nicholas Brealey.

Shafer, R. A., Dyer, L., Kilty, J., Amos, J., \& Ericksen, G. A. (2000). Crafting a human resource strategy to foster organizational agility: A case study (CAHRS Working Paper No: 00-08). Ithaca, NY: Cornell University, ILR School, Center for Advanced Human Resource Studies (CAHRS).

Shahrabi, B. (2012). The role of organizational learning and agility in change management in state enterprises: A customer-oriented approach. International Research Journal of Applied and Basic Sciences, 3(12), 2540-2547.

Sharifi, H., \& Zhang, Z. (1999). A methodology for achieving agility in manufacturing organisations: An introduction. International Journal of Production Economics, 62(1), 7-22.

Sharifi, H., \& Zhang, Z. (2001). Agile manufacturing in practice-Application of a methodology. International Journal of Operations \& Production Management,21(5/6), 772-794.

Shukla, M. (2013, January). To Study the Relationship Between Knowledge Utilization and Learning Capability in a Team. In Proceedings of the 10th International Conference on Intellectual Capital, knowledge Management and Organizational Learning: ICICKM 2013 (pp. 394-400). Academic Conferences Limited.

Slater, S. F., \& Narver, J. C. (1995). Market orientation and the learning organization. The Journal of marketing, 59(3), 63-74.

Som, H. M., Saludin, M. N., Shuib, M. S., Keling, M. F., Narsquo, M., \& Nam, Y. T. (2010). Learning organization elements as determinants of organizational performance of non-profit organizations (NPOs) in Singapore. International NGO Journal, 5(5), 116-127.

Somashekar, N. T. (2009). Commercial Banking. In Banking (pp. 1-26). New Delhi: New Age International. 
Su, G. (2011). Exploring Requirements of Agility for Knowledge Management. In Wissensmanagement (pp. 371-380).

Tallon, P. P., \& Pinsonneault, A. (2011). Competing perspectives on the link between strategic information technology alignment and organizational agility: insights from a mediation model. MIS Quarterly, 35(2), 463-486.

Tannenbaum, S. I. (1997). Enhancing continuous learning: Diagnostic findings from multiple companies. Human Resource Management, 36(4), 437-452.

Targeted News Service. (2016, January). USAF Acting Assistant Secretary Lombardi Issues Testimony on Acquisition Reform: Experimentation, Agility. Retrieved from https://search.proquest.com/docview/1779792919?accountid=16693

Teece, D. J. (2007). Explicating dynamic capabilities: the nature and microfoundations of (sustainable) enterprise performance. Strategic Management Journal, 28(13), 1319-1350.

Tohidi, H., Mohsen Seyedaliakbar, S., \& Mandegari, M. (2012). Organizational learning measurement and the effect on firm innovation. Journal of Enterprise Information Management, 25(3), 219-245.

Tsourveloudis, N. C., \& Valavanis, K. P. (2002). On the measurement of enterprise agility. Journal of Intelligent and Robotic Systems, 33 (3), 329-342.

Ulrich, D., Jick, T., \& Von Glinow, M. A. (1993). High-impact learning: Building and diffusing learning capability. Organizational Dynamics, 22(2), 52-66.

Vargas, M. I. R. (2013). Underlying Dimensions and Organizational Values in Organizational Learning: Strategy for Capacity Building in Developing Countries. Journal of Technology Management \& Innovation, 8(3), 57-69.

Walick, R. J. (1997). Mastering change--that thing you must do. Armed Forces Comptroller, 42(3), 45-56.

Wiklund, J., \& Shepherd, D. 2003. Knowledge-Based Resources, Entrepreneurial Orientation, and the Performance of Small and Medium-Sized Businesses. Strategic Management Journal, 24(13), 1307-1314.

Worley, C. G. (2009). Built to change: Creating agile and sustainably successful organization. Center for Effective Organizations. Retrieved from http://ceo.usc.edu/pdf/G10_02.pdf

Worley, C. G., \& Lawler, E. E. (2010). Agility and Organization Design:: A Diagnostic Framework. Organizational Dynamics, 39(2), 194-204.

Yaghoobi, N. M., \& Dahmardeh, M. R. (2010). Analytical approach to effective factors on organizational agility. Journal of Basic and Applied Scientific Research, 1(1), 76-87.

Yaghoobi, N. M., Kazemi, M., Dahmardeh, M. R., \& Arhami, F. (2011). Organizational Agility A Way to Import the Advantageous Aspects of Competitive Market (An Analytical-Comparative Approach on Agility Models). Interdisciplinary Journal of Contemporary Research in Business, 2(12), 766-783.

$\mathrm{Yu}, \mathrm{L} ., \quad \&$ Heng, Z. (2006, October). Measuring agility of enterprise using analytic hierarchy process and Bayesian belief networks. In 2006 International Conference on Management Science and Engineering ICMSE'06 (pp. 551-556). IEEE.

Yusuf, Y. Y., Sarhadi, M., \& Gunasekaran, A. (1999). Agile manufacturing:: The drivers, concepts and attributes. International Journal of production economics, 62(1), 33-43.

Zain, M., Kassim, N. M., \& Masrom, M. (2006). The Influence of IT on Organizational Agility in Malaysia. Oxford Journal: An International Journal of Business \& Economics, 1(1), 30-35.

Zeitun, R., \& Benjelloun, H. (2013). The efficiency of banks and the financial crisis in a developing economy: the case of Jordan. Journal of Finance, Accounting and Management, 4(1), 1-20.

Zhang, Z., \& Sharifi, H. (2000). A methodology for achieving agility in manufacturing organizations. International Journal of Operations \& Production Management, 20(4), 496-513.

Zimmer, M., Baars, H., \& Kemper, H. G. (2012, January). The impact of agility requirements on business intelligence architectures. In 2012 45th Hawaii International Conference on System Science HICSS (pp. 4189-4198). IEEE.

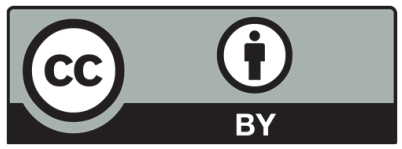

(C) 2017 by the authors; licensee Growing Science, Canada. This is an open access article distributed under the terms and conditions of the Creative Commons Attribution (CC-BY) license (http://creativecommons.org/licenses/by/4.0/). 